Acta vet. scand. 1990, 31, 505-507.

Brief Communication

\title{
Effects on Testosterone and LH Concentrations of Induced Testicular Degeneration in Bulls
}

Various environmental factors are known to influence gonadal function. Prolonged stress in man was found to have a suppressive effect on plasma testosterone concentrations (Aakvaag et al. 1978). Experimentally induced cryptorchidism in rats caused a considerable reduction in testosterone levels in the abdominal testicle (Berg \& Damber 1978). Heat stress has also an effect on cortisol levels. Aakvaag et al. (1978) and Larsson et al. (1983) showed that prolonged stress lead to increased cortisol levels and at the same time to decreased testosterone levels. In boars, treated with ACTH for 5 days, reduced testosterone concentrations were observed (Liptrap \& Raeside 1975).

Since hormonal changes have been found to occur after exposure of animals to heat stress, it is important to study the endocrine effects of local heating, thus avoiding exposure to any external stress of the animal. To our knowledge, no study has been performed on the effect of elevated scrotal temperature, after scrotal insulation in bulls, on hormone secretion.

The aim of this study was to describe the temporal changes in peripheral plasma concentrations of testosterone and $\mathrm{LH}$ during and after induced testicular degeneration (i.e. scrotal insulation) in bulls.

Two bulls, 1 Swedish Red and White (A), and 1 Swedish Friesian (B) 31 and 20 months old, respectively, were used in the study.

To induce testicular degeneration the scrotum was covered by an insulation device (double plastic bag with insulation). The duration of the scrotal insulation was $120 \mathrm{~h}$ (5 days).

To evaluate the effect of the scrotal insulation, semen was collected 3 times at weekly intervals before scrotal insulation, at the end of the insulation period, once a week during 6 weeks and then at 2 weeks intervals for 8 weeks.

Blood-samples were collected in vacutainer tubes at 4 sampling occasions, every $2 \mathrm{~h}$ for $22 \mathrm{~h}$ (12 samples): 1) before the scrotal insulation, 2) on day 4 of scrotal insulation, 3) 1 week after scrotal insulation and 4) 4 weeks after scrotal insulation.

Plasma concentration of testosterone and LH was determined by radioimmunoassay (Oltner et al. 1979, Madej et al. 1989).

The testosterone and $\mathrm{LH}$ values of the bulls before, during and after scrotal insulation are presented in Fig. 1 (bull A and B), as the area under the curve. The testosterone levels in bull $\mathbf{A}$ were higher than in bull $\mathbf{B}$, during the whole experimental period. During scrotal insulation the levels of testosterone showed a decline in both bulls. A week after scrotal insulation, the testosterone levels showed an increase, compared with the levels during scrotal insulation. Four weeks after scrotal insulation, a tendency to a decline in testosterone levels, compared with the levels before and 1 week after scrotal insulation, were seen. There were no distinct changes of the LH levels. In bull A there was a decline during the scrotal insulation period, but on the other hand there were no 


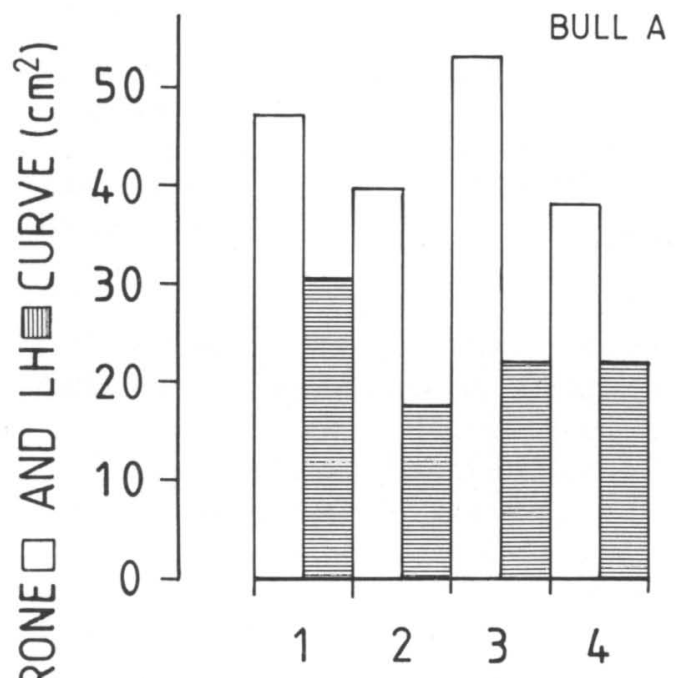

BULL B

$40-$
$30-$
$20-$
$10-$
$0-$

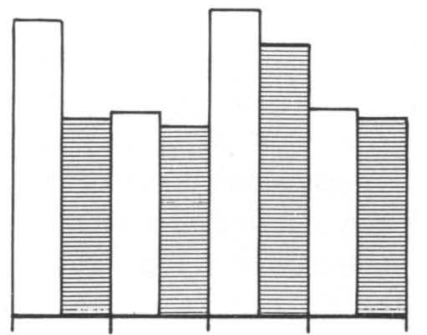

\section{SAMPLING OCCASION}

Figure 1. The figure shows the area under the testosterone $\square$ and LH 4 sampling occasions: 1 . Before scrotal insulation (SI). 2. On day 4 of SI. 3. One week after SI. 4. Four weeks after SI.

changes in bull B between the pre-treatment period and the scrotal insulation period (Fig. 1).

The decrease in plasma testosterone concentrations during scrotal insulation is in agreement with a similar study done in boars (Malmgren 1990). The changes are also in agreement with heat stress experiments (high environmental temperature) in bulls (Rhynes \& Ewing 1973), and in boars (Wetteman \& Desjardin 1979, Larsson et al. 1983).

In the present study using only insulation of the scrotum and with the bulls maintained in a familiar environment, one can assume that the stress factor on the animals was minimal. Thus, plasma cortisol levels may remain unaffected and should not cause a reduction in the plasma testosterone levels. It seems more likely that the changes in testosterone secretion are caused by a direct effect of the higher temperature on the testis. This was previously found by Berg \& Damber (1978) in rats, and by Skinner \& Rowson (1968) in lamb and calves, where lowered testosterone concentrations in experimentally induced cryptorchidism indicated impaired Leydig cells function.

The LH concentrations in peripheral plasma seemed not to be influenced by scrotal insulation or the lowered levels of testosterone, This is in agreement with Wetteman \& Desjardin (1979), who could see a decrease in testosterone concentration, but no changes in LH level after heat stress in boars. However, this was exposure of the whole body to heat and not only scrotal insulation. Maybe, the changes in testosterone concentration in this study are too small to influence the pituitary gland and cause alterations in the LH secretion. Also other hormomes of testicular origin, like e.g. inhibin, might be influenced by local or systemic heat stress. These hormones also interact with the hypothalamus-hypophysis axis and are at least partly involved in the $\mathrm{LH}$ response. To clarify this, more investigations need to be done. 


\section{Acknowledgement}

This work was supported by grants from SIPAR and the Swedish Council for Forestry and Agricultural Research.

Jetti Prabhakar,

The National Dairy Development Board, Anand, Gujarat, India.

Micus Chimbombi,

The Veterinary Office, Jwaneng, Botswana.

Lena Malmgren and Gunnar Fredriksson,

Department of Obstetrics and Gynaecology,

Swedish University of Agricultural Sciences, Uppsala, Sweden.

Andrzej Madej,

Department of Clinical Chemistry,

Swedish University of Agricultural Sciences,

Uppsala, Sweden.

\section{References}

Aakvaag A, Bentdal $\emptyset$, Quigstad K, Walstad P, Ronningen $H$, Fonnum $F$ : Testosterone and testosterone binding globuline (TeBG) in young men during prolonged stress. Int. J. Andr. 1978, 1, 22-31.

Berg A, Damber J-E: Morphometric and functional investigation on the Leydig cells in experimental unilateral cryptorschism in the rat. Int. J. Andr. 1978, 1, 549-562.
Larsson KS, Einarsson S, Lundström K, Hakkarainen $J$ : Endocrine effects of heat stress in boars. Acta vet. scand. 1983, 24, 305-314.

Liptrap RM, Raeside JI: Increase in plasma testosterone concentration after injection of adrenocorticotrophin into the boar. J. Endocrin. 1975, 66, 123-131.

Madej A, Hallin P, Madej M, Seguin B, Edquist $L-E$ : Influence of bovine $L H$ tracer quality on levels of LH in GnRH-treated cows. J. Immunoassay. 1989, 10, 270-300.

Malmgren L: Experimental induced testicular alterations in boars: Hormonal changes in mature and peripubertal boars. Acta vet. scand. 1990, 31, 97-107.

Oitner $R$, Lundström $K$, Edquist $L-E$ : $\mathrm{LH}$ and te-

... stosterone in monozygous growing bulls. Swedish J. agric. Res. 1979, 9, 151-161.

Rhynes WE, Ewing LL: Testicular endocrine function in Hereford bulls exposed to high ambient temperature. Endocrinol. 1973, 92, 509-515.

Skinner JD, Rowson LE: Some effects of unilateral cryptorchism and vasectomy on sexual development of the pubescent ram and bull. J. Endocr. 1968, 42, 311-321.

Wetteman RP, Desjardin C: Testicular function in boars exposed to elevated ambient temperature: Biol. Repr. 1979, 20, 235-241.

(Received August 27, 1990; accepted October 10, 1990).

Reprints may be requested from: L. Malmgren, Department of Obstetrics and Gynaecology, Swedish University of Agricultural Sciences, P. O. Box 7039, S-750 07 Uppsala, Sweden. 